\title{
ABORDAGEM URBANA (PARA)MÉTRICA EM ÁREAS DE HABITAÇÃO DE INTERESSE SOCIAL
}

\section{URBAN (PARA)METRIC APPROACH IN SOCIAL HOUSING NEIGHBORHOODS}

\author{
Fernando Tadeu de Araújo Lima ${ }^{1}$ \\ Universidade Federal de Juiz de Fora, Juiz de Fora, MG, Brasil, fernando.lima@arquitetura.ufjf.br. \\ Frederico Ribeiro Costa ${ }^{2}$ \\ Universidade Federal da Paraíba, João Pessoa, PB, Brasil, frederico.costa@arquitetura.ufjf.br. \\ Ashiley Adelaide Rosa ${ }^{3}$ \\ Universidade Federal de Juiz de Fora, Juiz de Fora, MG, Brasil, ashiley.rosa@arquitetura.ufjf.br. \\ Luiza Fischer Costa Vallone ${ }^{4}$ \\ Universidade Federal de Juiz de Fora, Juiz de Fora, MG, Brasil, luiza.vallone@arquitetura.ufjf.br.
}

\begin{abstract}
Resumo
No cenário recente da produção de habitações de interesse social no Brasil, com especial ênfase no contexto do programa Minha Casa Minha Vida (MCVC), há uma prevalência de relatos de precariedade de infraestrutura e serviços urbanos. Neste contexto, diversos autores apontam a necessidade de análises mais aprofundadas destes aspectos para a aprovação de empreendimentos MCMV. Este artigo descreve uma abordagem computacional que visa a fornecer suporte para tarefas de avaliação e de proposição urbana em empreendimentos de baixa renda e em suas áreas circunvizinhas. Para tal, ferramentas do sistema computacional CityMetrics foram implementadas em dois empreendimentos MCMV na cidade de Juiz de Fora (MG), em um caso de estudo que objetivou: i) calcular índices relacionados à caminhabilidade, à diversidade de usos e à densidade construída para análise das áreas estudadas e; ii) identificar, com base nas análises, os melhores locais para inserção de serviços urbanos na área de abrangência destes empreendimentos. Os resultados apontam que a abordagem utilizada contribuiu para a obtenção de melhores índices nas áreas estudadas e que as ferramentas de CityMetrics podem ser úteis para: i) analisar propostas de empreendimentos a serem viabilizados e; ii) para indicar localizações para novos serviços urbanos, em empreendimentos já consolidados.
\end{abstract}

Palavras-chave: Habitação de interesse social. CityMetrics. Caminhabilidade. Diversidade de usos. Densidade construída.

\begin{abstract}
In the current scenario of social housing production in Brazil, with particular emphasis on the context of the Minha Casa Minha Vida (MCVC) program, there is a prevalence of reports about precarious infrastructure and urban services. Several authors point out the need for a more in-depth analysis of these aspects before MCMV project approval in this context. This article describes a computational approach that supports the assessment and proposition of low-income housing developments and their surrounding areas. To this end, CityMetrics tools were implemented in two MCMV projects in the city of Juiz de Fora (MG). A case study aimed to calculate indexes related to walkability, diversity, and density for analyzing the studied areas. Another case study to identify, based on the analysis, the best places to insert urban services in the area covered by these projects. The results show that the approach used contributed to obtaining better indexes in the studied areas. CityMetrics tools can help analyze proposals for projects to be made feasible and indicate new urban services in existing projects.
\end{abstract}

Keywords: Social housing. CityMetrics. Walkability. Diversity of Uses. Built Density.

How to cite this article:

LIMA, F. T. de A.; COSTA, C. F. R.; ROSA, A. A..; VALLONE, L. F. C. Abordagem urbana (para)métrica em áreas de habitação de interesse social. PARC Pesquisa em Arquitetura e Construção, Campinas, SP " v. 11, p. e020024, 2020. DOI: http://dx.doi.org/10.20396/parc.v11i0.8657220 


\section{Introdução}

De acordo com Lima (2017), o paradigma de organização e crescimento adotado pelas cidades tem sido relacionado a grandes complicações no cotidiano dos centros urbanos contemporâneos (dependência do automóvel, padrões espaciais fragmentados, menos interações sociais). O planejamento de cidades para uma organização espacial mais eficiente e integrada, por sua vez, é o método mais eficaz para reduzir o impacto do transporte urbano e promover uma vida social mais interativa (LIMA, 2017). Nesse sentido, o desenvolvimento de abordagens de planejamento que considerem os princípios da caminhabilidade, da diversidade de usos e da densidade das áreas urbanas torna-se cada vez mais importante, sobretudo em áreas urbanas de baixa renda. Curiosamente, é possível encontrar áreas residenciais de baixa renda espontaneamente consolidadas em que estes princípios se manifestam de maneira intensa (VERNIZ; DUARTE, 2020), enquanto a maioria dos empreendimentos recentes e planejados sob o escopo do programa Minha Casa Minha Vida (MCMV) posicionam empreendimentos em áreas urbanas remotas e distantes dos serviços urbanos básicos, o que resulta no agravamento de uma série de problemas sociais (ZAMBRANO, 2015). Por outro lado, o design computacional e os procedimentos algorítmicos-paramétricos têm possibilitado uma nova lógica de construção e tratamento das informações relativas aos processos de planejamento urbano, de maneira a permitir abordar situações complexas em ambientes computacionais e simulação e verificação de alternativas, permitindo a exploração de múltiplos cenários. As variáveis geradas parametricamente em um sistema generativo fornecem maneiras de gerenciar grandes quantidades de dados e de processar possíveis interações entre eles. Ferramentas de otimização podem permitir que as decisões sejam tomadas com mais eficiência e baseadas em evidências, o que viabiliza a identificação de configurações mais adequadas para o papel que edifícios, ruas e vizinhanças desempenham em uma rede de mobilidade urbana, por exemplo. Portanto, o objetivo principal deste estudo é apresentar uma abordagem suportada por recursos computacionais, que pode ser implementada para analisar e propor alterações na localização, na concentração e na distribuição de serviços no contexto de áreas residenciais de baixa renda, com base em índices relacionados à caminhabilidade, à diversidade de usos e à densidade.

Neste contexto, este trabalho apresenta os resultados de uma pesquisa elaborada no âmbito do Laboratório de Investigação em Arquitetura e Urbanismo (DOMVS Cnpq) da Universidade Federal de Juiz de Fora, cujo escopo é a aplicação do sistema computacional CityMetrics, desenvolvido por Lima (2017), em tarefas de análise e de otimização que busquem identificar fragilidades dos bairros estudados, objetivando aprimorar: (i) a localização / distribuição dos serviços urbanos básicos nas áreas estudadas, com a intenção de minimizar distâncias de deslocamento e promover maior facilidade de locomoção, e; (ii) o equilíbrio entre áreas residenciais e não residenciais no ambiente urbano que envolve os dois empreendimentos imobiliários de baixa renda estudados, visando assim, promover uma maior diversidade de usos e uma maior vitalidade urbana. Este artigo também apresenta uma implementação computacional dos Indicadores de Densidade Spacematrix, propostos por Berghauser Pont e Haupt (2010) e que foram utilizados para apoiar as análises elaboradas. Neste cenário, este artigo se desenvolve por meio da seguinte sequência: i) uma breve revisão sobre ferramentas computacionais e sobre os princípios da caminhabilidade, da diversidade de usos e da densidade urbana, bem como sua importância para auxiliar no desenvolvimento de projetos urbanos de áreas com maior vitalidade e que sejam mais integradas e sustentáveis; ii) uma descrição e uma apresentação do sistema computacional CityMetrics, empregado neste estudo; iii) algumas reflexões sobre o 
contexto dos empreendimentos e bairros de baixa renda no Brasil; iv) uma implementação de CityMetrics em um caso de estudo que lida com dois diferentes empreendimentos no contexto do programa MCMV; v) uma apresentação e uma discussão sobre os resultados obtidos; e vi) uma discussão geral e conclusões sobre a pesquisa em questão.

\section{Caminhabilidade, diversidade de usos, densidade construída e aplicação de ferramentas computacionais para análises urbanas: uma breve revisão bibliográfica}

Este trabalho aborda, em síntese, três princípios básicos que devem ser considerados na proposição de cidades mais sustentáveis, mais integradas e com maior equidade social, são eles: i) a caminhabilidade - a habilidade que uma determinada área urbana tem de conectar locais de habitação e serviços urbanos básicos por meio de distâncias que podem ser percorridas a pé; ii) a diversidade de usos - princípio que preconiza um mix de usos, densidades e tipos de habitação no mesmo bairro, e; iii) a densidade princípio que incentiva a compactação e a ocupação nos bairros existentes, permitindo que sistemas de mobilidade funcionem mais eficientemente (CALTHORPE; FULTON, 2001; CERVERO; KOCKELMAN, 1997; DITTMAR; OHLAND, 2004; SUZUKI; CERVERO; IUCHI, 2013).

\section{Caminhabilidade}

Gehl (2013) argumenta que a cidade tende a se tornar mais viva à medida que mais pessoas são convidadas a caminhar, a pedalar ou a permanecer em espaços públicos, interagindo, trocando informações, oportunidades sociais e culturais. Caminhar em um bairro que possui serviços urbanos variados conectados por uma curta distância é, sem dúvida, uma atividade muito mais agradável do que caminhar por regiões onde estes estão distantes e dispersos. Assim, áreas mais caminháveis tendem a trazer mais pessoas para o convívio no espaço urbano. De acordo com Farr (2013), e em resumo, a caminhabilidade consiste na habilidade de um determinado bairro de conectar residências, pontos de comércio e outros serviços por distâncias que podem ser percorridas a pé, conferindo maior autonomia, menor dependência do automóvel e uma rede viária que permite a vida urbana e opções de transporte.

De acordo com o índice Walkscore, desenvolvido por Brewster et al. (2009), a caminhabilidade ideal considera distâncias pedonais de até 40om percorridos ( $5 \mathrm{~min}$ de caminhada), apresentada pelos autores como o "paraíso da caminhabilidade", até os $1,6 \mathrm{~km}$ percorridos (20 minutos de caminhada), quando então eles referem que passa a ser necessário a incorporação de algum outro modal de transporte.

Diversidade de usos

Calthorpe (1993) defende que um uso diversificado na escala de vizinhança é um fatorchave para a sustentabilidade das cidades, reforçando a importância de bairros multifuncionais. Rogers (1997), por sua vez, defende o uso misto e a diversidade de usos em diversas esferas para um melhor aproveitamento dos espaços, em uma lógica onde tudo acontece simultaneamente: viver, trabalhar, consumir e entreter-se em uma mesma área, que visa a atender à lógica de posicionar serviços e comércios sem a necessidade de grandes deslocamentos. Nesse contexto, bairros com vários tipos de usos e serviços incentivam as pessoas a se locomover, potencializando o contato e a integração de pessoas de diferentes culturas e classes, melhorando a qualidade de interação e vida social como um todo. 
Hoek (2008) apresentou, no âmbito de um estudo que buscou desenvolver o índice de uso misto Mixed-use Index (MXI), os parâmetros para estabelecer uma relação ideal de mistura urbana, referindo que o ideal seria o equilíbrio exato, ou seja: de acordo com o autor, metade das áreas construídas deveriam ser residenciais e a outra metade nãoresidenciais.

\section{Densidade construída}

A densidade em áreas urbanas é uma ideia defendida por vários autores (CHAKRABARTI, 2013; DANTZIG; SAATY, 1973; FARR, 2013; GEHL, 2013; GLAESER, 2011; LEITE, 2012; ROGERS, 1997; SUZUKI; CERVERO; IUCHI, 2013). Rogers (1997), aponta que cidades compactas são sustentáveis porque proporcionam um ótimo desempenho energético, reduzem a poluição e o consumo de recursos, e oferecem as vantagens de morar perto do local de trabalho e do outro, em busca da redescoberta da proximidade. De acordo com Stuchi e Leite (2019), o conceito de cidade compacta é baseado em três pilares: otimização de recursos, inovação e sustentabilidade.

\section{Ferramentas computacionais para análise urbana}

Embora ainda não sejam implementadas com a mesma popularidade como no campo específico da arquitetura, aplicações computacionais para o contexto urbano têm sido crescentemente desenvolvidas nos últimos anos (LIMA, 2017; LIMA; COSTA; ROSA, 2020). Os componentes que constituem um bairro ou uma cidade também possuem similaridades que podem ser definidas parametricamente, e existem várias ferramentas e modelos nesse contexto. As obras de Duarte et al. (2012), Beirão (2012), Montenegro (2015) e Nourian et al. (2015), além de confirmar o grande potencial das aplicações computacionais em situações urbanas, abordam questões relacionadas às configurações urbanas, morfologia urbana, ontologia urbana, caminhabilidade, entre outras. Existem ainda, outros modelos e/ou ferramentas que podem ser utilizados em contextos semelhantes - conforme exposto por Lima, Costa e Rosa (2020) - como o Urban Network Analysis (SEVTSUK; MEKONNEN, 2012) e o Urbano Toolbox (DOGAN; SAMARANAYAKE; SARAF, 2018). Entretanto, a abordagem adotada nesta pesquisa utiliza o sistema CityMetrics, um conjunto de ferramentas elaboradas em um ambiente algorítmico-paramétrico, que também visa a fornecer análises em um ambiente computacional mais dinâmico (plug-in Grasshopper), abordando índices e métricas de caminhabilidade, de diversidade de usos e de densidade urbana.

\section{CityMetrics}

O sistema CityMetrics (Figura 1), desenvolvido por Lima (2017) e aplicado nos trabalhos de Lima e Silva (2019), Lima et al. (2019a), entre outros, consiste em um conjunto de ferramentas elaboradas no ambiente do Grasshopper e destinadas a auxiliar em tarefas de análise e planejamento urbano. Este sistema se apresenta sob a forma de ferramentas especificamente projetadas para avaliar o desempenho de áreas urbanas sob a perspectiva dos princípios (e de métricas) da caminhabilidade, da diversidade de usos e da densidade, e, consequentemente, visa a auxiliar no desenvolvimento de projetos urbanos que priorizem a proposição de bairros e cidades mais socialmente vibrantes e sustentáveis. É importante ressaltar que o modelo não se destina a atuar como um solucionador automático independente. Assim, segundo Lima (2017) o papel dos muitos atores envolvidos nas tarefas de planejamento urbano permanece central, e ainda são esses atores que serão responsáveis por estabelecer objetivos, alimentar o sistema e considerar outros aspectos "não programáveis" e subjetivos envolvidos nesse processo. 
Neste sentido, o modelo computacional CityMetrics Toolbox consiste nas seguintes ferramentas: (i) Algoritmo de Proximidade Física (APF) - uma ferramenta que mede a distância entre um alvo (um serviço urbano) e um (ou todos os) local(is) em uma vizinhança (origens). Nesse sentido, o algoritmo proposto calcula o(s) caminho(s) com distância(s) física(s) menor(es) entre um alvo e um (ou todos) destino(s) em um dado recorte urbano, considerando declive(s) no(s) caminho(s); (ii) Algoritmo de Proximidade Topológica (APT) - uma ferramenta que calcula a proximidade considerando métricas topológicas, usando conceitos da teoria da Sintaxe Espacial (HILLIER; HANSON, 1984); (iii) Algoritmo de Variedade de Serviços (AVS) - uma ferramenta que calcula a distância média entre uma determinada fonte e todos os alvos próximos em uma determinada categoria de serviços urbanos; (iv) Algoritmo de Recorrência de Serviços (ARS) - calcula a proporção do número de alvos relatados (em cada categoria de serviços) e o número total de locais em uma área pesquisada; (v) Algoritmo de Uso Misto (AMXI) - estabelece uma relação entre a soma de todas as áreas residenciais e não residenciais de uma localidade, fazendo uma comparação dessas proporções (HOEK, 2008; LIMA, 2017; LIMA, 2019); e (vi) Algoritmo de Indicadores Spacematrix - calcula os atributos relacionados à densidade construída nas áreas estudadas, informando três indicadores fundamentais propostos por Berghauser Pont e Haupt (2010): aproveitamento do solo (Floor Space Index, FSI), ocupação do solo (Ground Space Index, GSI) e Densidade de Rede (Network Density, N) (LIMA, 2017; LIMA et al., 2019a).

Desta forma, na medida em que CityMetrics possibilita abordar índices de avaliação relacionados aos princípios da caminhabilidade, da diversidade de usos e da densidade construída de maneira paramétrica, pretende-se verificar o potencial de utilização de ferramentas deste sistema para analisar a implantação de empreendimentos Minha Casa Minha Vida (MCMV) a serem viabilizados, bem como para indicar localizações para novos serviços urbanos em empreendimentos já consolidados.

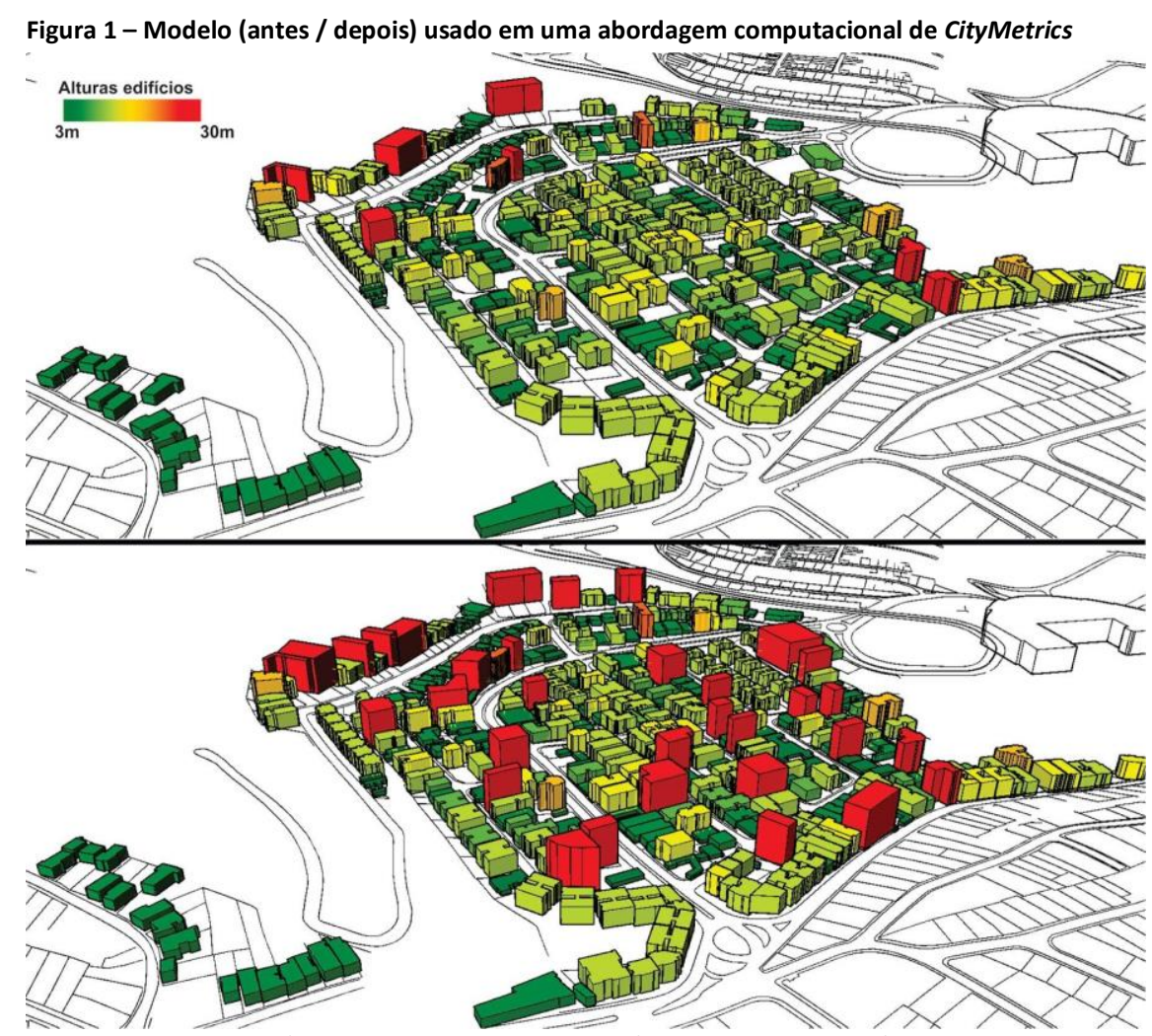

Nota: pontos, curvas, sólidos e outras entidades geométricas usadas para análise urbana relacionadas a características de caminhabilidade, diversidade de usos e densidade construída. Fonte: Adaptado de Lima (2017). 


\section{Habitação de interesse social no Brasil e o programa "Minha Casa Minha Vida"}

O programa Minha Casa Minha Vida (MCMV) é uma política do Governo Federal do Brasil que tem como objetivo principal suprir o déficit habitacional do país, por meio de iniciativas que impulsionam o setor de construção civil. O MCMV teve a intenção de atuar em parceria com estados, municípios, empresas e instituições públicas e privadas, por meio de um programa denominado "Programa de Aceleração do Crescimento" (PAC) (BRASIL, 2011).

A primeira fase do MCMV compreendeu os anos de 2009 e 2010. Já a segunda fase, compreendeu os anos entre 2011 e 2014. Mais recentemente, a terceira fase, anunciada em 2016, esperava a conclusão das obras em 2018. Atualmente, o MCMV atende famílias com 4 faixas de rendimento (em reais): i) faixa 1, até 1.800 ; ii) faixa 1,5 , até 2.600 ; iii) faixa 2, até 4.000 e; iv) faixa 3, até 7.000 (CAIXA, 2019). As famílias que compõem a faixa 1 recebem o maior subsídio do governo, que podem chegar a até $95 \%$ do valor da propriedade, estas são as Habitação de Interesse Social (HIS). O MCMV foi muito criticado enquanto sua implementação, principalmente, por fatores como: i) a falta de articulação dos projetos com o espaço urbano; ii) a reprodução indiscriminada de tipologias em larga escala e; iii) o impacto na infraestrutura urbana, especialmente aqueles que abrigam a população de baixa renda (MURAT, 2015).

\section{MCMV na cidade de Juiz de Fora}

A cidade de Juiz de Fora, objeto espacial de nosso estudo, é um município de médio porte, localizado na região sudeste de Minas Gerais, na região da Zona da Mata mineira. A área total do município é de $1.429,875 \mathrm{~km}^{2}$ (extensão territorial compatível com o da cidade de São Paulo, que é de $1.521,11 \mathrm{~km}^{2}$ ) e sua população estimada é de 564.310 habitantes (IBGE, 2018). Segundo Zambrano (2018), Juiz de Fora apresenta uma produção significativa de projetos do programa MCMV em relação ao déficit habitacional brasileiro; no entanto, a autora levanta críticas e questionamentos sobre os seus resultados e impactos para a cidade. Nas fases 1 e 2 do MCMV (2009 a 2014), foram produzidos 16 projetos em Juiz de Fora, para a faixa 1, totalizando 3.615 unidades habitacionais. Os critérios locais de prioridade no sorteio das habitações foram: i) famílias em risco social (sem renda, renda social); ii) famílias que moram na cidade há mais de dois anos e; iii) famílias com dois ou mais filhos em idade escolar.

Ainda segundo Zambrano (2018), a prevalência de relatos de precariedade de infraestrutura e serviços urbanos mostra que o município deve priorizar a análise desses aspectos ao aprovar a implementação de novos projetos MCMV, uma vez que, segundo a autora, se os locais onde foram implantados já estavam precários antes da implantação, essa precariedade foi ampliada com o aumento da demanda por serviços e com a inclusão de um número grande de famílias nesses locais (ZAMBRANO, 2018).

Nesse contexto, é possível afirmar que, em geral, os projetos do MCMV em Juiz de Fora (e no Brasil) são implementados em áreas remotas da cidade, com baixa mobilidade, baixa diversidade de usos e baixa densidade. Portanto, esses bairros de baixa renda possuem poucos serviços urbanos próximos, estão localizados em áreas predominantemente residenciais e com baixa concentração de pessoas e oportunidades de encontro, o que tende a aprofundar uma série de problemas de ordem social que atingem os moradores desta região. 


\section{Caso de estudo}

Os empreendimentos Miguel Marinho e Araucárias, mapeados neste caso de estudo (Figura 2 e Figura 4), foram selecionados com base em suas diferenças, que são: i) a tipologia das edificações; ii) a escala do projeto e; iii) a localização / inserção na rede urbana. O Residencial Miguel Marinho está localizado na região norte do município, próximo ao limite da área urbana e é composto por 86 casas de dois andares e quatro unidades por lote, totalizando 344 unidades habitacionais. O residencial Araucárias, por sua vez, está localizado na região sul de Juiz de Fora e é constituído por 380 unidades habitacionais, distribuídas em 19 edifícios de cinco andares, com quatro apartamentos por andar. Embora possuam tipologias diferentes e estejam localizados em diferentes regiões da cidade, ambos os projetos têm dificuldades semelhantes em relação a questões de caminhabilidade, diversidade de usos e densidade.

Figura 2 - Identificação dos dois empreendimentos analisados na cidade de Juiz de Fora, Minas Gerais, Brasil

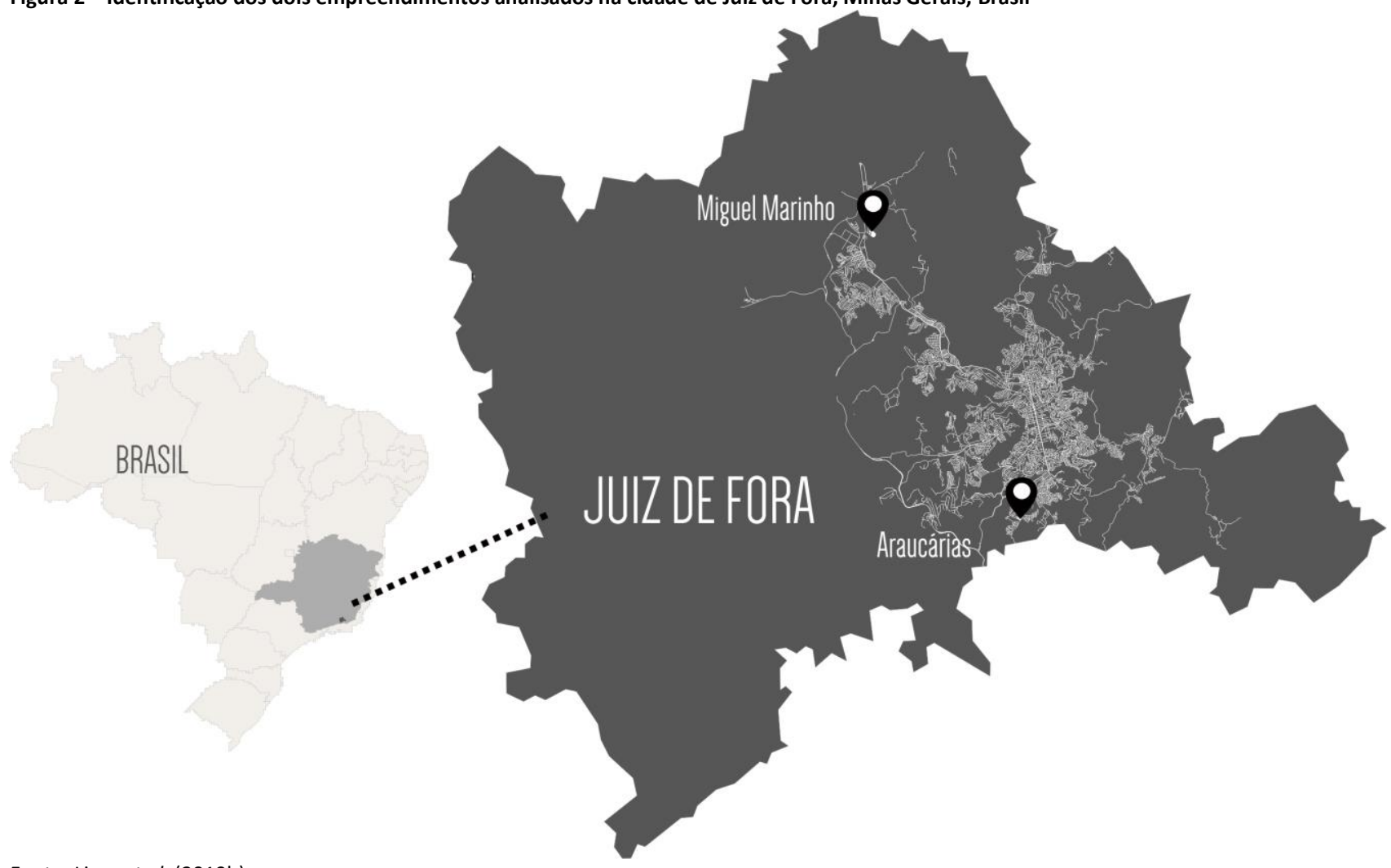

\section{Procedimentos metodológicos}

Do ponto de vista metodológico, esta investigação aplica o método indutivo, delineando-se como uma pesquisa aplicada, de caráter exploratório e de abordagem quali-quantitativa. Nesse âmbito, a implementação de CityMetrics e os procedimentos metodológicos adotados neste estudo, podem ser divididos em quatro etapas distintas: i) o levantamento e o tratamento de informações relativas às áreas abordadas, bem como a preparação dos arquivos para cálculo dos índices referentes às ferramentas de CityMetrics, ou seja, a obtenção e preparação dos dados a serem manipulados na análise urbana e, posteriormente, na otimização computacional; ii) o cálculo e a análise dos índices obtidos pelas ferramentas de CityMetrics, construindo o cenário atual das áreas estudadas sobre os aspectos da caminhabilidade, da diversidade de usos e da densidade construída; iii) a comparação dos resultados obtidos na análise das áreas em estudo com os indicadores de desempenho para a caminhabilidade a diversidade de usos e a 
densidade construída; e iv) a utilização destes índices como referência para tarefas de otimização computacional, visando à identificação de alterações nas áreas urbanas (como a indicação de localização para novos serviços urbanos) que venham a aprimorar os índices inicialmente identificados nas áreas abordadas. A Figura 3 sintetiza as etapas deste estudo.

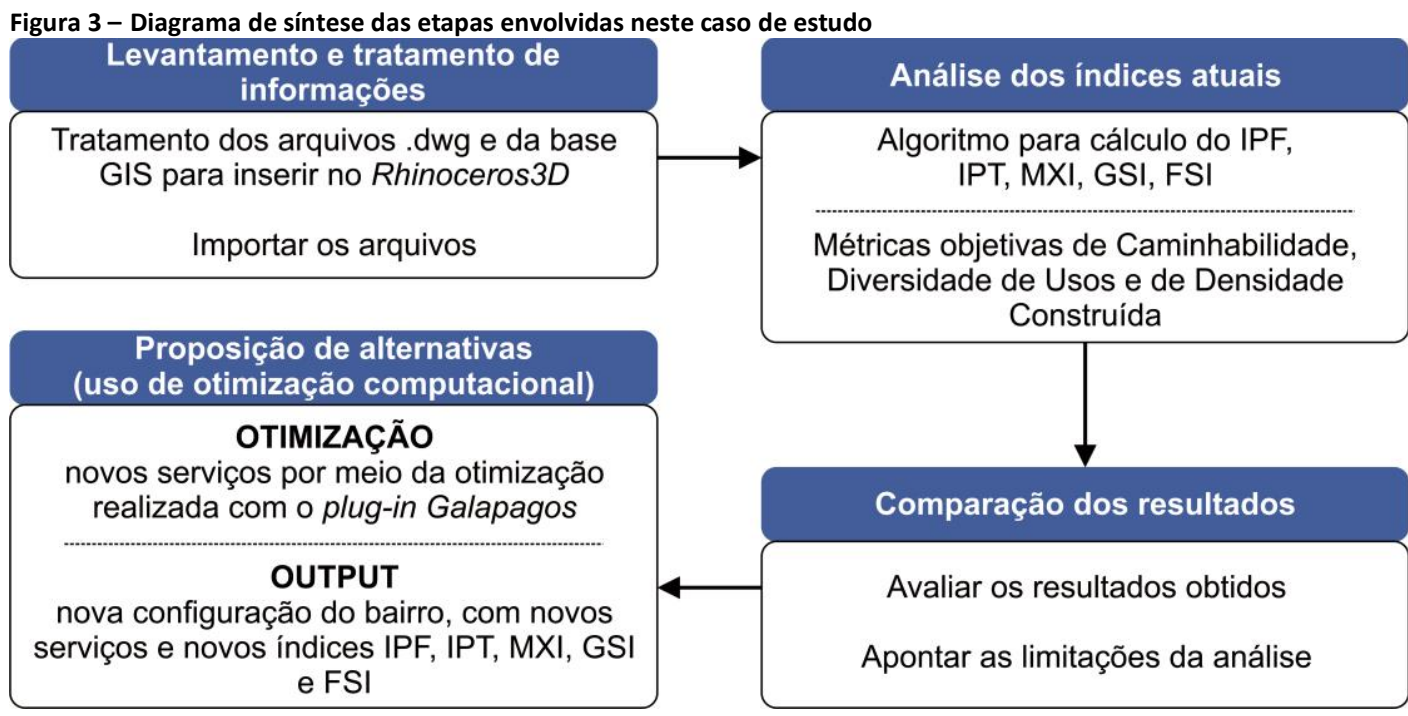

Fonte: os autores.

Mais especificamente, durante a etapa de análise dos índices, foram desenvolvidas as seguintes tarefas: i) mensurar e comparar índices relacionados à caminhabilidade (Proximidade Física e Proximidade Topológica) dos dois empreendimentos, considerando os serviços urbanos mais próximos; ii) mensurar e comparar seus índices de Uso Misto - IMX; iii) mensurar e comparar seus indicadores relacionados à densidade - Spacematrix.

Neste contexto, foi utilizado um modelo paramétrico em ambiente Rhinoceros3D / Grasshopper para gerenciar as entidades geométricas que foram associadas a elementos urbanos: i) pontos representaram a localização dos edifícios e se referiam a diferentes funções urbanas (por exemplo, educacional, comércio, comida, lazer, entre outros); ii) curvas simularam a rede existente de ruas; e iii) sólidos foram utilizados para emular o papel de edifícios. A identificação dos serviços urbanos dentro da área de estudo foi feita por meio de um mapeamento que utilizou os dados fornecidos pela ferramenta Google Maps, considerando um raio de 1,5 km. Assim, os serviços urbanos foram classificados em 8 categorias, sendo elas: i) Saúde - composta por hospitais, unidades de pronto atendimento e Unidades Básicas de Saúde; ii) Educacional composto por instituições de ensino fundamental e médio; iii) Abastecimento - incluindo supermercados, padarias e mercearias; iv) Alimentação - composta por lanchonetes, bares e restaurantes; v) Comércio - composto por farmácias e lojas que vendem produtos de necessidade básica; vi) Entretenimento - composto por teatros, cinemas, casas de cultura; vii) Recreação - espaços como quadras, campos de futebol, praças e clubes; viii) Outros - contendo todos os outros serviços que não se enquadram nas categorias anteriores, como bancos e serviços institucionais, por exemplo. A análise de diversidade de usos e de densidade construída foi feita considerando todos os edifícios em seu entorno imediato, em um raio de $1 \mathrm{~km}$ (Figura 4).

Em seguida, na etapa de proposição de alternativas, a ferramenta Galapagos, de otimização computacional para o Grasshopper, foi utilizada para indicar modificações na organização dos bairros, apontando onde novos serviços urbanos (considerando as 
LIMA, F. T. de A.; COSTA, C. F. R.; ROSA, A. A..; VALLONE, L. F. C.

Abordagem urbana (para)métrica em áreas de habitação de interesse social

categorias apresentadas anteriormente) deveriam ser localizados, a fim de aumentar os índices relativos à caminhabilidade e à diversidade de usos dos bairros.

Figura 4 - Localização dos dois projetos (Construções em preto) e seus arredores imediatos.

Residencial Araucárias

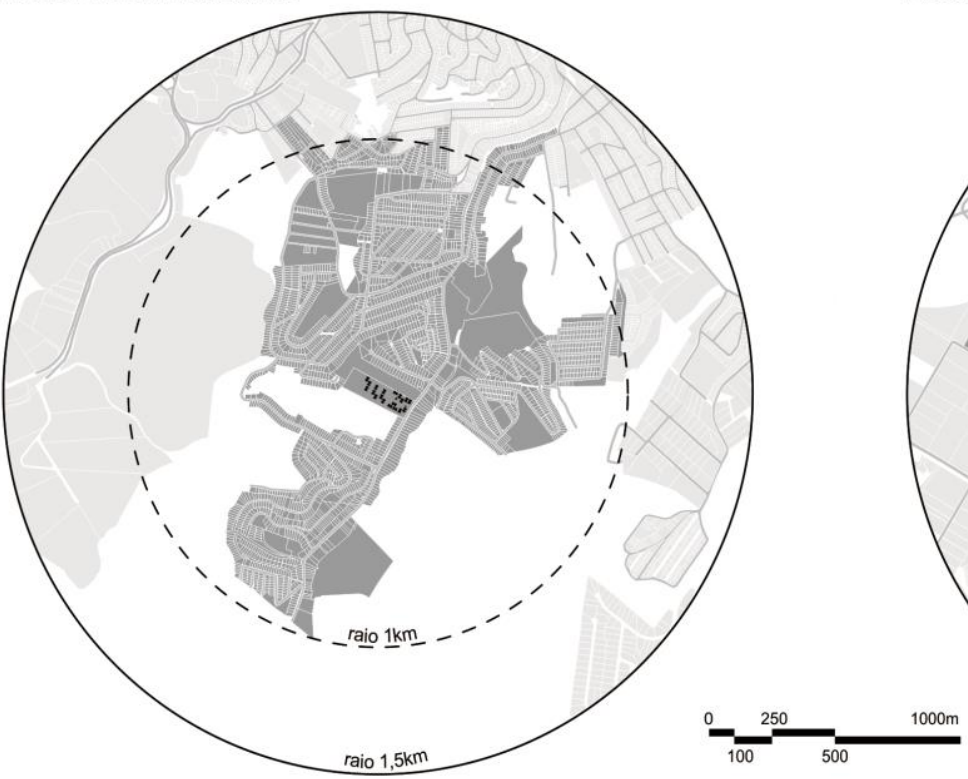

Residencial Miguel Marinho

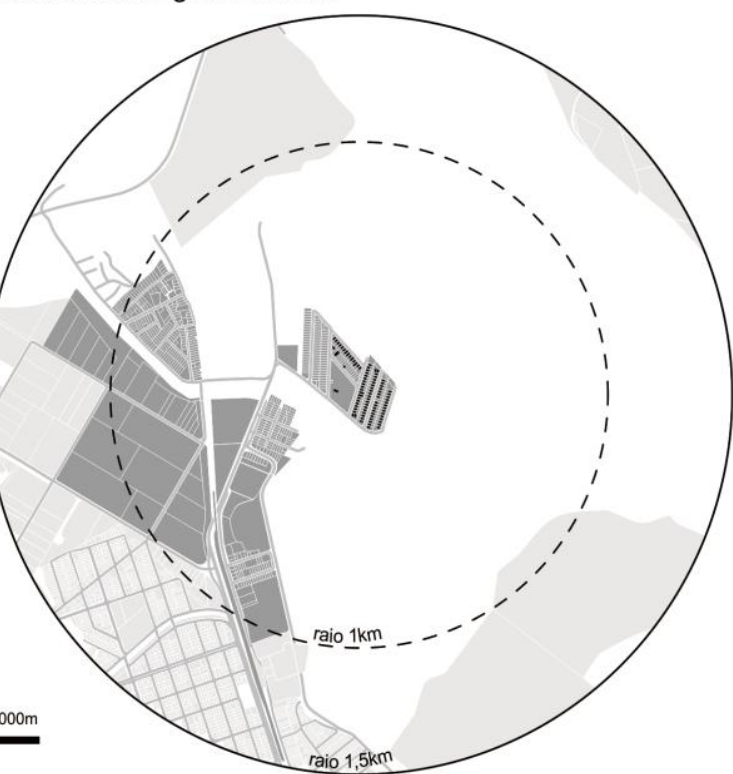

Nota: Em cinza escuro, área considerada nas análises de diversidade de usos e de densidade construída. Em cinza claro, área considerada para o estudo de caminhabilidade (Proximidade física e topológica). Fonte: os autores.

\section{Resultados}

Tratando especificamente dos indicadores de densidade construída (Tabela 1), é possível afirmar que as duas áreas estudadas apresentam baixos índices de ocupação e de aproveitamento do solo (traduzido em valores baixos de GSI, FSI), especialmente se comparadas com os outros dois bairros de classe média/alta de Juiz de Fora indexados e também com áreas urbanas consolidadas nas cidades de Amsterdam, Barcelona e Berlim (Figura 5).

Tabela 1 - Informações gerais sobre os empreendimentos abordados (Araucárias e Miguel Marinho) e índices relativos à caminhabilidade, à diversidade de usos e à densidade construída antes da proposição de novos serviços nos bairros

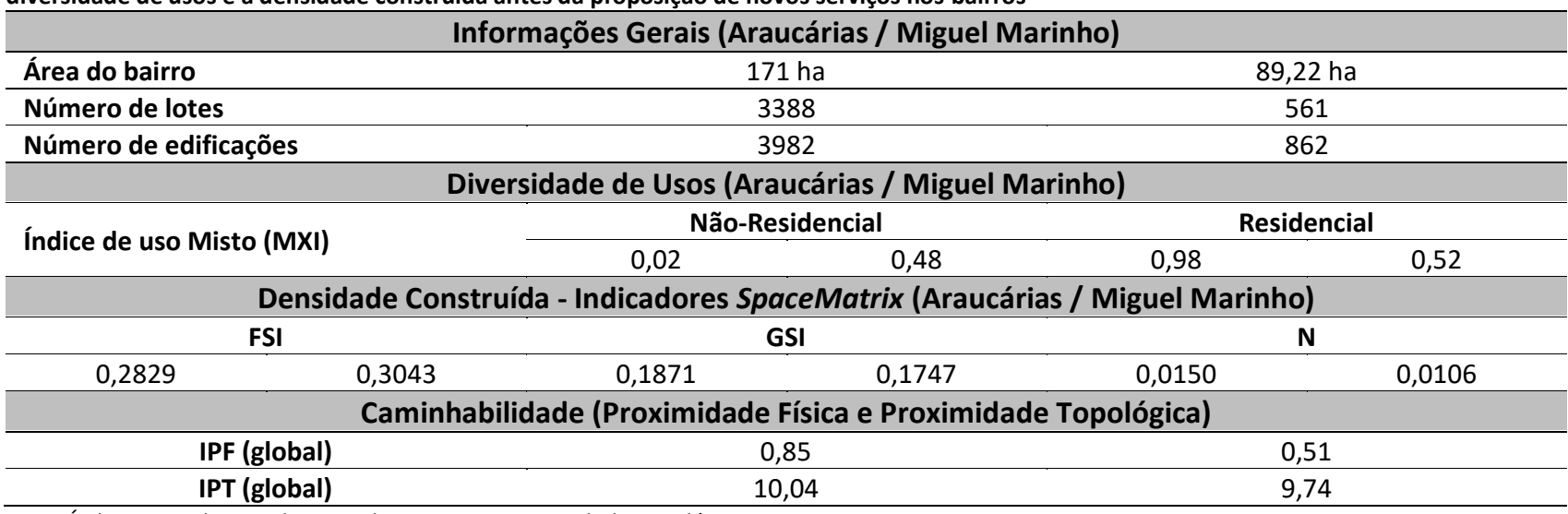

Nota: Índices mais baixos de IPT indicam maior proximidade topológica. Fonte: os autores. 
Figura 5 - Representação gráfica dos indicadores de densidade Spacematrix nos dois empreendimentos (números 1 e 2)

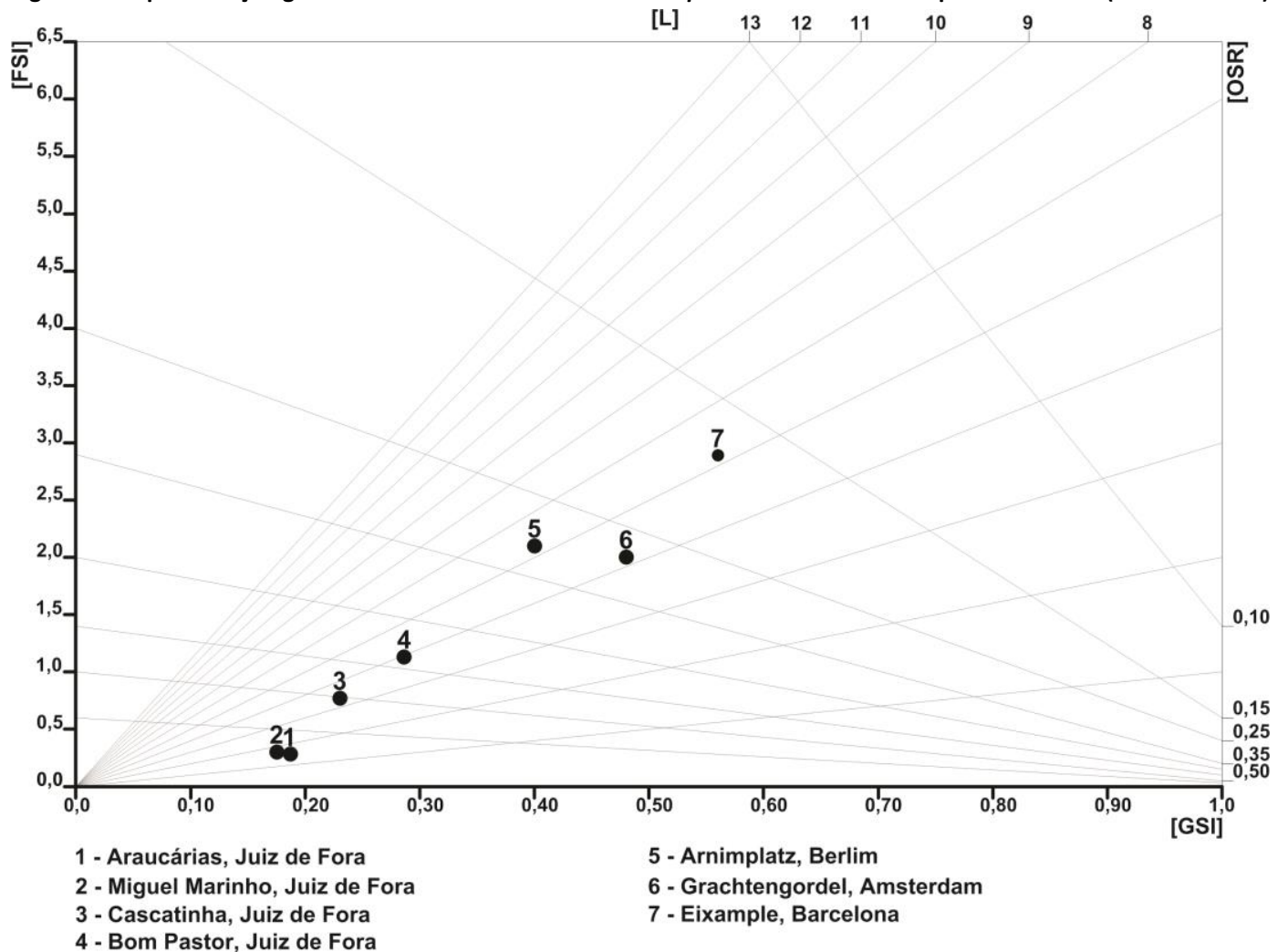

Nota: No gráfico, é possível comparar os indicadores GSI e FSI das áreas estudadas nesta investigação (números 1 e 2) com dados de outras duas áreas localizadas em dois bairros de classe média/alta da cidade de Juiz de Fora (números 3 e 4 , no gráfico) estudados por Lima et al. (2019b) e com exemplos de diferentes áreas em Berlim, Amsterdam e Barcelona (números 5, 6 e 7) indexados por Berghauser Pont e Haupt (2010), enriquecendo a discussão sobre as relações entre fragmentação espacial e social. Fonte: os autores.

Comparando os resultados obtidos nos dois bairros, os algoritmos responsáveis por calcular índices relacionados a caminhabilidade (APF e APT) indicam que há pouco incentivo à mobilidade pedonal nas duas áreas (Tabela 2 e Tabela 3): no empreendimento Araucárias, das oito categorias de serviços consideradas por este estudo, cinco se encontravam acima dos 400 metros de distância recomendados, resultando proximidade física média igual a 532,15 metros (IPF Global $=0,85$ ). Já no Miguel Marinho, das oito categorias duas eram inexistentes na área de estudo, com outras cinco categorias distando mais do que 400 metros do conjunto habitacional, resultando em uma proximidade física média igual a 666,34 metros (IPF Global =0,51).

As tarefas de otimização empregadas permitiram identificar os melhores locais para sugerir a locação de novos serviços em ambos os bairros, considerando as categorias mencionadas anteriormente (ver Figuras 6 e 8). Assim, a inserção de um serviço para cada categoria resultou em melhores índices IPT e IPF, sugerindo maior caminhabilidade e também maior diversidade de usos para os bairros (ver Tabelas 2 e 3 e Figuras 7 e 9). Em alguns casos, foi sugerida a inserção de serviços que não existiam anteriormente nas proximidades do bairro Miguel Marinho. Embora isso, aparentemente, signifique um aumento no índice IPT (e consequentemente um pior desempenho), na realidade o que se obteve foi mais diversidade de usos e oferta de serviços para a vizinhança tratada. Esta distorção se dá, pelo fato de que, ao não existir previamente um determinado serviço em uma categoria, o índice não é contabilizado e a média neste caso diminui. Ao inserir um serviço o índice aumenta, sugerindo maior distância topológica média, o que não reflete necessariamente a realidade. 
LIMA, F. T. de A.; COSTA, C. F. R.; ROSA, A. A..; VALLONE, L. F. C.

Abordagem urbana (para)métrica em áreas de habitação de interesse social

\begin{tabular}{|c|c|c|c|c|c|c|c|c|}
\hline \multicolumn{9}{|c|}{ Índice de Proximidade Física (IPF) para Serviços (média) } \\
\hline \multirow{3}{*}{ Categoria } & \multicolumn{4}{|c|}{ Araucárias } & \multicolumn{4}{|c|}{ Miguel Marinho } \\
\hline & \multicolumn{2}{|c|}{ IPF (média) } & \multicolumn{2}{|c|}{ Distância (m) } & \multicolumn{2}{|c|}{ IPF (média) } & \multicolumn{2}{|c|}{ Distância (m) } \\
\hline & antes & depois & antes & depois & antes & depois & antes & depois \\
\hline Saúde & 1,00 & 1,00 & 210,56 & 210,56 & 0,00 & 0,94 & - & 426,77 \\
\hline Educacional & 0,76 & 1,00 & 666,59 & 347,02 & 0,60 & 0,96 & 734,67 & 406,60 \\
\hline Abastecimento & 1,00 & 1,00 & 364,51 & 364,51 & 0,24 & 0,99 & 1259,41 & 331,40 \\
\hline Alimentação & 0,97 & 1,00 & 434,56 & 186,57 & 0,53 & 1,00 & 934,50 & 316,38 \\
\hline Comércio & 1,00 & 1,00 & 336,99 & 297,49 & 0,84 & 0,99 & 448,04 & 341,41 \\
\hline Entretenimento & 0,47 & 1,00 & 1023,03 & 287,02 & 0,00 & 0,98 & - & 336,84 \\
\hline Recreação & 0,91 & 1,00 & 506,21 & 355,73 & 0,98 & 0,99 & 284,15 & 284,15 \\
\hline Outros & 0,72 & 1,00 & 714,75 & 342,01 & 0,90 & 0,98 & 337,30 & 337,30 \\
\hline IPF (global) & 0,85 & 1,00 & 532,15 & 298,86 & 0,51 & 0,98 & 666,34 & 347,61 \\
\hline
\end{tabular}

Nota: Índices mais altos de IPF indicam maior proximidade física. Fonte: Lima et al. (2019b).

Tabela 3 - Índice de Proximidade Topológica (IPT) antes e depois da proposição de novos serviços nos bairros

\begin{tabular}{lcccc}
\hline \multirow{2}{*}{\multicolumn{1}{c}{ Índice de Proximidade Topológica (IPT) para Serviços (média) }} \\
\cline { 2 - 5 } & \multicolumn{2}{c}{ Araucárias } & \multicolumn{2}{c}{ Miguel Marinho } \\
\cline { 2 - 5 } & \multicolumn{2}{c}{ IPT (média) } & \multicolumn{2}{c}{ IPT (média) } \\
\cline { 2 - 5 } Saúde & 12,04 & 11,86 & - & 12,75 \\
\hline Educacional & 7,95 & 7,70 & 10,01 & 9,93 \\
\hline Abastecimento & 6,79 & 6,60 & 10,28 & 9,91 \\
\hline Alimentação & 10,05 & 10,02 & 9,84 & 9,76 \\
\hline Comércio & 5,58 & 5,52 & 9,39 & 9,38 \\
\hline Entretenimento & 13,27 & 12,94 & - & 12,76 \\
\hline Recreação & 9,20 & 8,99 & 9,62 & 9,60 \\
\hline Outros & 15,47 & 6,57 & 9,27 & 9,26 \\
\hline IPF (global) & 10,04 & 8,77 & 9,74 & 10,42 \\
\hline
\end{tabular}

Nota: Pouca diversidade de usos, baixa verticalização e densidade em ambos os projetos.

Miguel Marinho tem um MXI equilibrado "falso" devido à proximidade do distrito

industrial da cidade. Fonte: os autores.

Figura 6 -Posicionamento dos serviços urbanos existentes na área circunvizinha ao empreendimento Araucárias

Residencial Arauc
Antes
IPF: 0,85
IPT: 10,04

$\square$ Alimentação
$\square$ Recreação
Entretenimento
Educacional
Abastecimento
Comércio
Saúde
Outros
Inserções

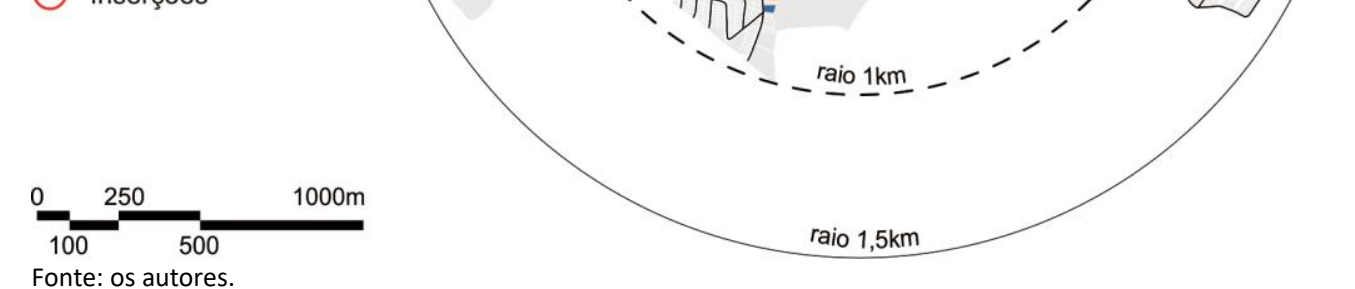


LIMA, F. T. de A.; COSTA, C. F. R.; ROSA, A. A..; VALLONE, L. F. C.

Abordagem urbana (para)métrica em áreas de habitação de interesse social

Figura 7 -Posicionamento dos serviços urbanos segundo as alterações propostas no experimento da área circunvizinha ao empreendimento Araucárias

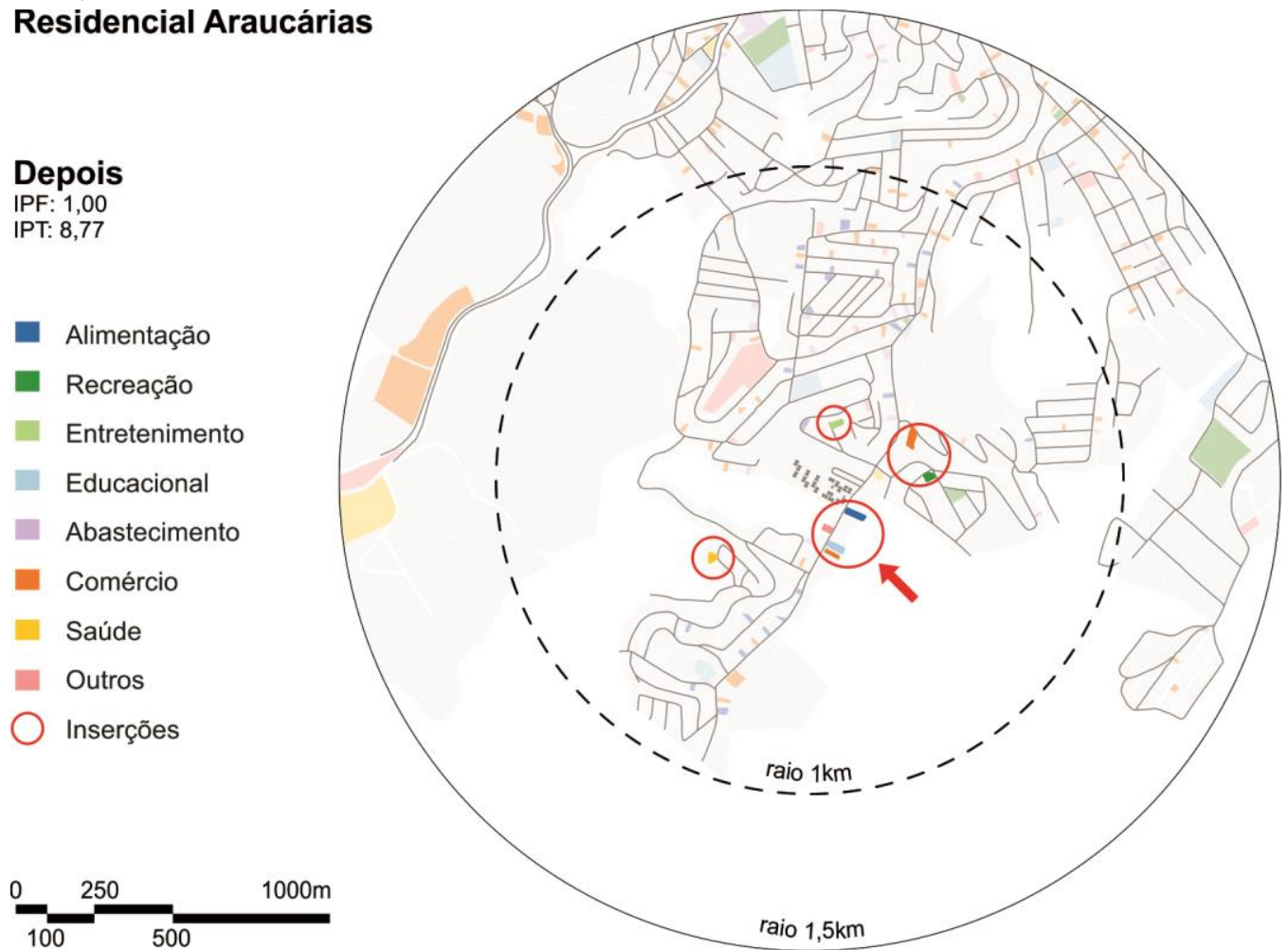

Nota: Os serviços urbanos inseridos após otimização computacional (circulados em vermelho) geraram melhores índices relacionados à Proximidade Física e à Proximidade Topológica, sugerindo uma maior caminhabilidade. Fonte: os autores.

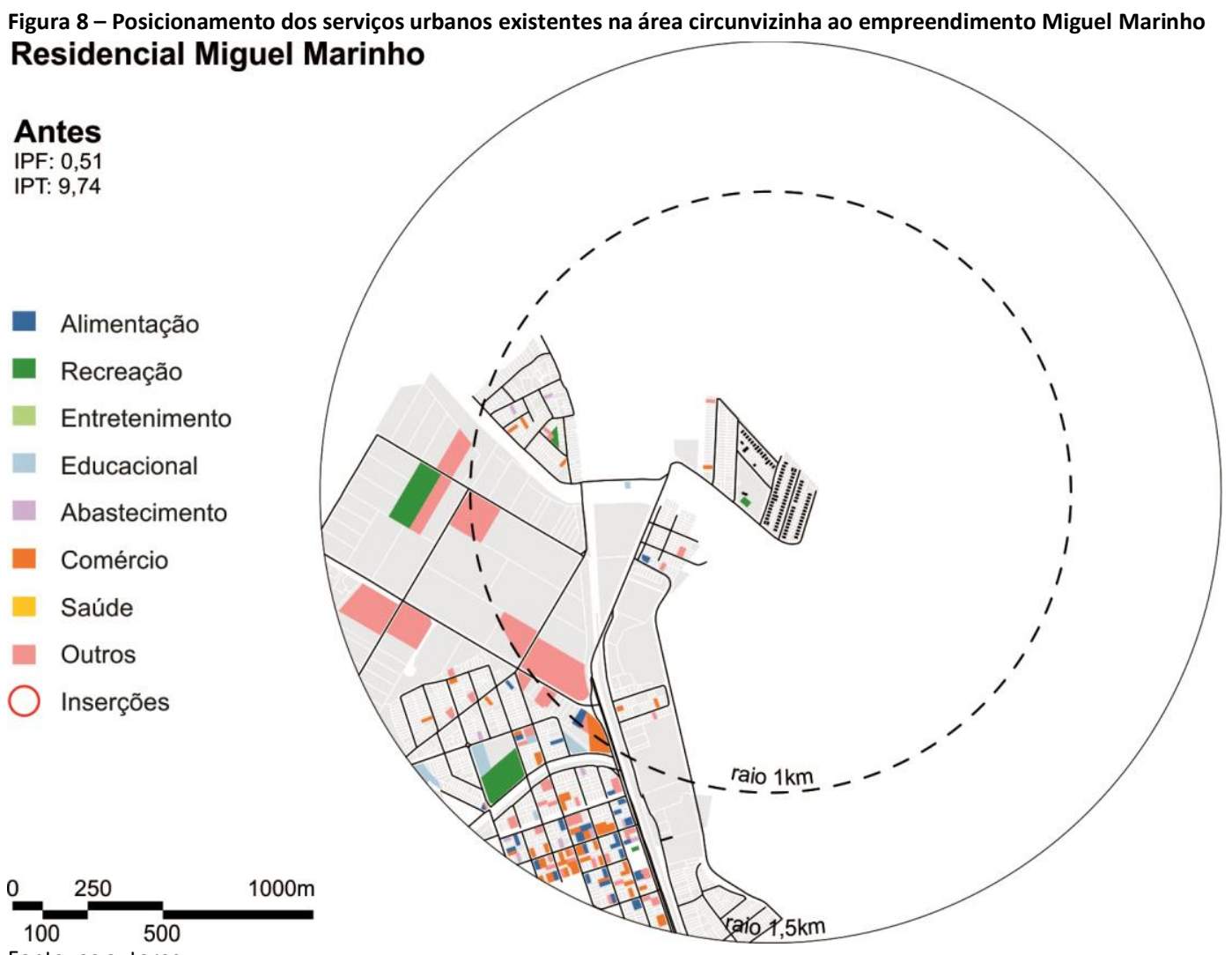


LIMA, F. T. de A.; COSTA, C. F. R.; ROSA, A. A..; VALLONE, L. F. C.

Abordagem urbana (para)métrica em áreas de habitação de interesse social

Figura 9 - Posicionamento dos serviços urbanos segundo as alterações propostas no experimento da área circunvizinha ao empreendimento Miguel Marinho

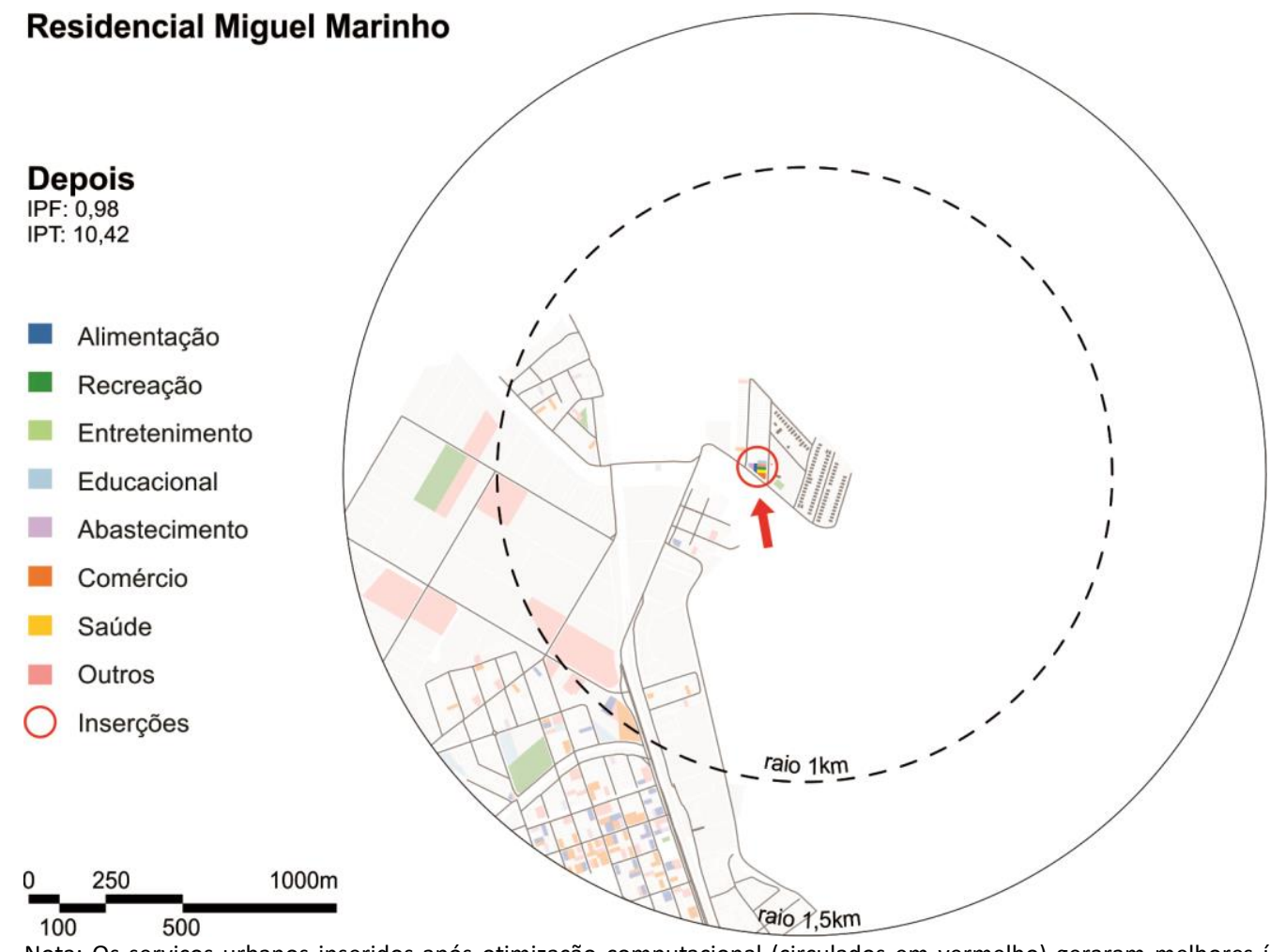

Nota: Os serviços urbanos inseridos após otimização computacional (circulados em vermelho) geraram melhores índices relacionados à Proximidade Física e à Proximidade Topológica, sugerindo uma maior caminhabilidade. Fonte: os autores.

Em relação a diversidade de usos (Tabela 1, Figura 10 e Figura 11), o algoritmo de uso misto AMXI apontou que o entorno do empreendimento Araucárias é excessivamente monofuncional, destinando-se predominantemente ao uso residencial (98\%). No caso do Miguel Marinho, os resultados obtidos foram influenciados pelo fato de existirem indústrias em seu entorno imediato, traduzido em um AMXI apontando equilíbrio de usos ( $48 \% / 52 \%)$, o que não significa que os habitantes tenham acesso a uma ampla gama de serviços, como é possível perceber por meio dos resultados dispostos na Tabela 2 e na Tabela 3, que apresentam a distância em metros e em passos topológicos entre o conjunto habitacional e as oito categorias de serviços aqui analisadas.

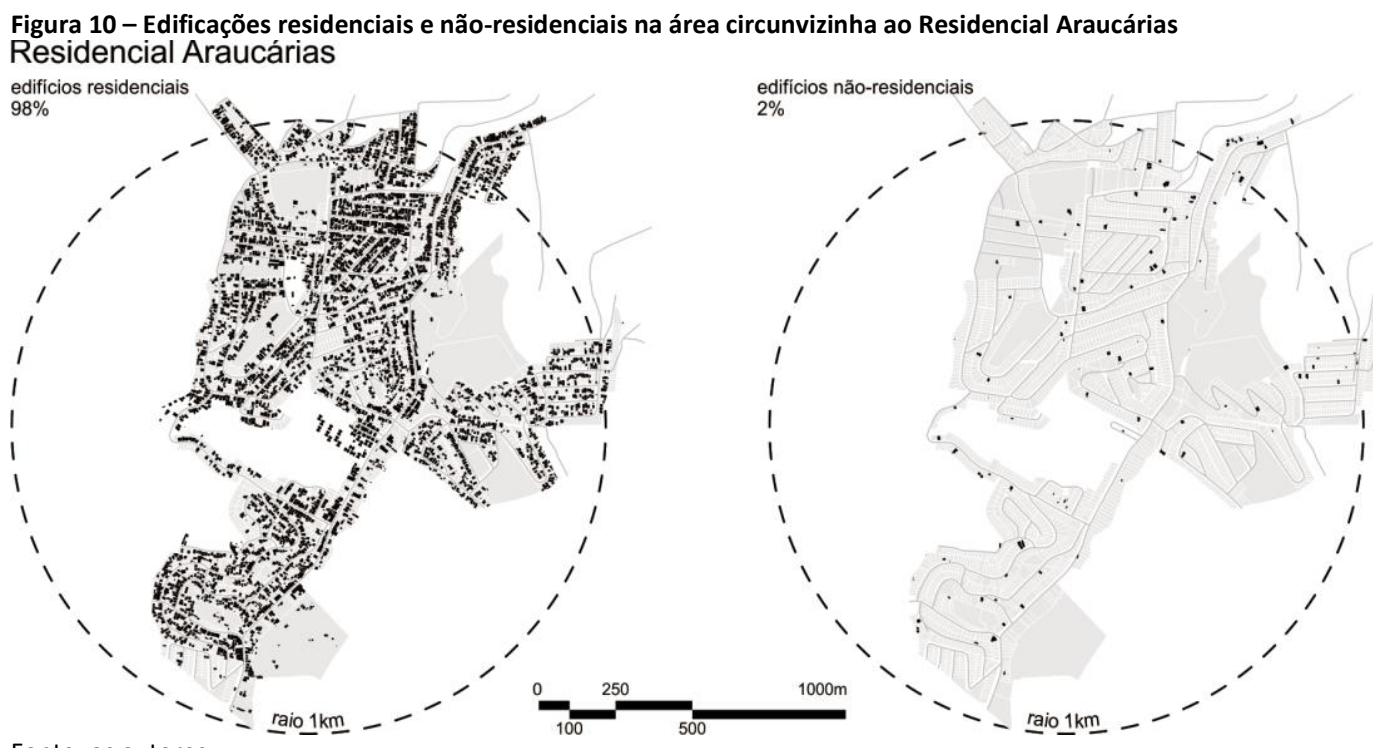

Fonte: os autores. 


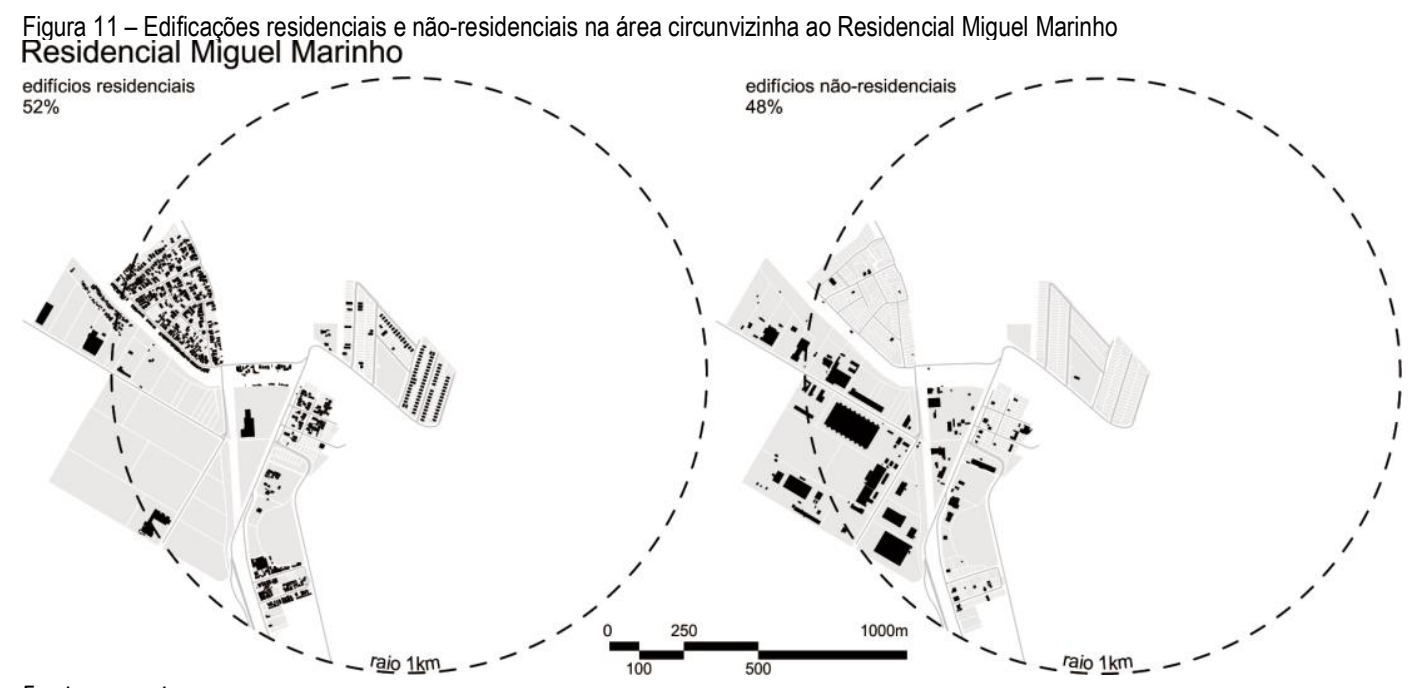

Fonte: os autores.

\section{Discussões}

Mesmo considerando os benefícios advindos da utilização de uma ferramenta computacional para suporte à análise e à proposição urbana, os autores identificam algumas limitações na abordagem apresentada, são elas: i) o Índice de Proximidade Física e o Índice de Proximidade Topológica não incorporam totalmente as diversas características que podem influenciar a caminhabilidade dentro de uma área urbana, pois existem outros fatores que também estão envolvidos neste contexto, especialmente de ordem qualitativa e subjetiva, como a qualidade das calçadas ou a sensação de segurança das pessoas que circulam pelas ruas, e; ii) conforme afirmado anteriormente, a densidade construída tem um papel fundamental no âmbito de promover cidades mais equilibradas e, sendo assim, variáveis relacionadas à densidade populacional e à implementação de modais em uma vizinhança também poderiam ter sido testadas.

Os autores deste artigo acreditam que abordagens como a que foi aqui apresentada possuem potencial para auxiliar não apenas na alteração de contextos urbanos existentes, mas também para avaliar cenários para aprovação de empreendimentos. $O$ uso de ferramentas computacionais, nesta perspectiva, pode significar empregar abordagens de verificação mais dinâmica - em que seria possível visualizar de antemão, por exemplo, quais seriam as condições de caminhabilidade, diversidade e densidade de uma área em que se pretende implementar um determinado projeto. Assim, tais parâmetros poderiam ser incorporados como parte das exigências para formalização de empreendimentos mais caminháveis, mais diversos e mais adequados para a parcela da população a que são destinados.

\section{Considerações finais}

Esta investigação buscou enfatizar a necessidade de se repensar a forma como os projetos MCMV são implementados no Brasil, destacando que esses empreendimentos devem ser implantados em áreas mais consolidadas, com serviços urbanos próximos e infraestrutura adequadas, sob o risco de se agravar ainda mais uma série de fragilidades sociais dos moradores que habitam as edificações destas vizinhanças. Neste cenário, é fundamental pensar em maneiras de se avaliar aspectos relacionados à caminhabilidade, à diversidade de usos e à densidade construída como requisito para aprovação de empreendimentos desta natureza. 
A abordagem aqui apresentada se mostrou potencialmente útil para contribuir neste sentido, uma vez que os experimentos elaborados permitiram verificar possibilidades de se incrementar as configurações urbanas das vizinhanças estudadas, em relação à existência e ao posicionamento de serviços urbanos, bem como sobre o equilíbrio entre diferentes usos. Assim, foi possível propor, avaliar e retroalimentar cenários que permitiriam tornar as áreas estudadas mais viáveis e diversificadas. Neste contexto, trata-se uma importante contribuição para uma lógica de suporte ao processo de análise e de tomada de decisão em contextos urbanísticos, no que tange ao contexto MCMV.

Este artigo, portanto, pretendeu contribuir no sentido de demonstrar o potencial de abordagens computacionais - mais especificamente do sistema CityMetrics - enquanto instrumento de suporte de planejamento para análise, viabilização e melhoria de empreendimentos MCMV, Objetivou-se, ainda, neste estudo específico sobre empreendimentos do programa MCMV, explorar aspectos sobre o habitar a cidade, bem como contribuir para o desenvolvimento de uma abordagem computacional direcionada a comunidades urbanas mais caminháveis, diversas e intensas (sobre o ponto de vista das interrelações sociais).

\section{Agradecimentos}

Agradecemos ao Laboratório de Investigação em Arquitetura e Urbanismo (DOMVS CNPq) e à professora Dra. Letícia Zambrano, coordenadora do Núcleo de Estudos em Habitação (NEHab) da Universidade Federal de Juiz de Fora, pelo apoio e contribuições dadas ao desenvolvimento desta investigação.

\section{Notas}

(1) Uma versão compacta desse artigo foi publicada nos Proceedings da Conferência Conjunta eCAADe e SIGraDi em Lima et al. (2019b).

\section{Referências}

BEIRÃO, J. CltyMaker / Designing Grammars for Urban Design. 2012. 272 f. Tese (Doutorado em Urbanismo) Faculdade de Arquitetura, Delft University of Technology, Delft, 2012.

BRASIL. Lei n 12.424, de 16 de junho de 2011. Altera a Lei nº 11.977, de 7 de julho de 2009, que dispõe sobre o Programa Minha Casa, Minha Vida - PMCMV, e outras. Diário Oficial [da] República Federativa do Brasil, Brasília, DF, 17 jun. 2011. Disponível em: http://www.planalto.gov.br/ccivil_03/_ato2011-2014/2011/Lei/L12424.htm. Acesso em: 11 maio. 2019.

BREWSTER, M.; HURTADO, D.; OLSON, S.; YEN, J. Walkscore.com: A New Methodology to Explore Associations Between Neighborhood Resources, Race, and Health. In: APHA ANNUAL MEETING AND EXPOSITION, 137., 2009, Philadelphia. APHA Poster Presentation. Philadelphia: APHA. 2009. Disponível em:

https://www.walkscore.com/professional/walkability-research.php. Acesso em: 23 ago. 2020.

CAIXA. Minha Casa Minha Vida - Habitação Urbana. 2019. Disponível em:

http://www.caixa.gov.br/voce/habitacao/minha-casa-minha-vida/urbana/Paginas/default.aspx. Acesso em: 11 de maio. 2019.

CALTHORPE, P. The next American metropolis: ecology, community and the American dream. Nova York: Princeton Architectural Press, 1993.

CALTHORPE, P.; FULTON, W. The regional city: planning for the end of sprawl. Washington: Island Press, 2001.

CERVERO, R.; KOCKELMAN, K. Travel demand and the 3Ds: density, diversity, and design. Transportation Research Part D: Transport and Environment, v.2, n.3, p. 199-219, 1997. DOI: https://doi.org/10.1016/S1361-9209(97)00009-6 
LIMA, F. T. de A.; COSTA, C. F. R.; ROSA, A. A..; VALLONE, L. F. C.

Abordagem urbana (para)métrica em áreas de habitação de interesse social

CHAKRABARTI, V. A country of cities. Nova York: Metropolis Books, 2013.

DANTZIG, G.; SAATY, T. Compact City: A plan for a liveable urban environment. São Francisco: W. H. Freeman, 1973.

DITTMAR, H.; OHLAND, G. (Org.). The new transit town: Best practices in Transit-Oriented Development.

Washington: Island Press, 2004.

DOGAN, T.; SAMARANAYAKE, S.; SARAF, N. Urbano: A New Tool to Promote Mobility-Aware Urban Design, Active Transportation Modeling and Access Analysis for Amenities and Public Transport. In: ANNUAL SYMPOSIUM ON SIMULATION FOR ARCHITECTURE AND URBAN DESIGN - SimAUD, 9., 2018, Delft. Proceedings [... ]. Delft: Delft University of Technology, 2018. DOI: https://doi.org/10.22360/simaud.2018.simaud.028.

DUARTE, J. P.; BEIRÃO, J. N.; MONTENEGRO, N.; GIL, J. City Induction: A Model for Formulating, Generating, and Evaluating Urban Designs. In: ARISONA, S., ASCHWANDEN, G., HALATSCH, J., WONKA, P. (Eds.). Digital Urban Modeling and Simulation. Berlim: Springer Berlin Heidelberg, 2012. p. 73-98.

FARR, D. Urbanismo sustentável: Desenho urbano com a natureza. Porto Alegre: Bookman, 2013.

GEHL, J. Cidades para Pessoas. São Paulo: Perspectiva, 2013.

GLAESER, E. Os centros urbanos: a maior invenção da humanidade: como as cidades nos tornam mais ricos, inteligentes, saudáveis e felizes. Nova York: Penguin, 2011.

HILLIER, B.; HANSON, J. The social logic of space. Cambridge: Cambridge University Press, 1984.

IBGE. Cidades: Juiz de Fora. 2018. Disponível em: https://cidades.ibge.gov.br/brasil/mg/juiz-de-fora/panorama. Acesso em: 11 de maio. 2019.

HOEK, J. The MXI (Mixed use Index). An instrument for anti-sprawl policy? In: INTERNATIONAL SOCIETY OF CITY AND REGIONAL PLANNERS CONGRESS, 44., 2008, Dalian. Proceedings [... ]. Dalian: Urban Planning Society of China, 2008. Disponível em: http://www.isocarp.net/Data/case_studies/1195.pdf. Acesso em: 23 ago. 2020.

LEITE, C. Cidades sustentáveis cidades inteligentes: Desenvolvimento sustentável num planeta urbano. Porto Alegre: Bookman, 2012.

LIMA, F. Métricas Urbanas: Sistema (para)métrico para análise e otimização de configurações urbanas de acordo com métricas de avaliação de desempenho. Rio de Janeiro, 2017. Tese (Doutorado em Urbanismo) - Faculdade de Arquitetura e Urbanismo, Universidade Federal do Rio de Janeiro, Rio de Janeiro, 2017.

LIMA, F.; SILVA, G. (Para)metric representations and urban indicators: an application of CityMetrics in a neighborhood of João Pessoa, Brazil In: JANEIRO, P. A. (Ed.). Imagined-architectures: architecture graphical representation and "other images" "drawing (...) City (...) body, dwelling on earth". Leiden: CRC Press, 2019. p. 3744 .

LIMA, F.; COSTA, F. R.; ROSA, A. Lógica algorítmica-paramétrica e urbanismo: uma revisão teórica e de modelos computacionais para projetos urbanos. Gestão e Tecnologia de Projetos, São Carlos, v.15, n.2, p.84-97, 2020. DOI: http://dx.doi.org/10.11606/gtp.162710

LIMA, F.; MONTENEGRO, N.; PARAÍZO, R.; KOS, J. Citymetrics: sistema (para)métrico para análise e otimização de configurações urbanas. Oculum Ensaios, v.16, n.2, p.409-427, 2019a. DOI: https://doi.org/10.24220/2318-

0919 v16n2a4163

LIMA, F.; VALLONE, L.; COSTA, C. F.; ROSA, A. (Para)metric Evaluation of Walkability, Diversity and Density in Lowincome Neighborhoods: Using the CityMetrics toolbox. In: EDUCATION AND RESEARCH IN COMPUTER AIDED ARCHITECTURAL DESIGN IN EUROPE, 37.; IBEROAMERICAN SOCIETY OF DIGITAL GRAPHICS, JOINT CONFERENCE, 23., 2019, Porto. Proceedings [...]. Porto: Faculdade de Arquitetura da Universidade do Porto, 2019b. $257-266$. 
LIMA, F. T. de A.; COSTA, C. F. R.; ROSA, A. A..; VALLONE, L. F. C.

Abordagem urbana (para)métrica em áreas de habitação de interesse social

MONTENEGRO, N. CityPlan: Contributo para o desenvolvimento de uma metodologia e ferramenta computacional para apoio ao desenho urbano. 2015. 440 f. Tese (Doutorado em Urbanismo) - Faculdade de Arquitetura, Universidade de Lisboa, Lisboa. 2015.

MURAT, M. G. O impacto no entorno das habitações de interesse social do Programa Minha Casa, Minha Vida em Juiz de Fora, Minas Gerais. Dissertação (Mestrado) - Departamento de Arquitetura e Urbanismo. Programa de Pósgraduação em Arquitetura e Urbanismo. Universidade Federal de Viçosa. Viçosa, 2015.

NOURIAN, P.; REZVANI, S.; SARIYILDIZ, S.; HOEVEN, F. Configurbanist: Urban Configuration Analysis for Walking and Cycling via Easiest Paths. In: EDUCATION AND RESEARCH IN COMPUTER AIDED ARCHITECTURAL DESIGN IN EUROPE, 33., 2015, Viena. Proceedings [...]. Viena: Universidade Técnica de Viena, 2015. 553-564.

BERGHAUSER PONT, M.; HAUPT, P. Spacematrix: Space, Density and Urban Form. Rotterdam: NAi Publishers, 2010.

ROGERS, R. Cidades para um pequeno planeta. Barcelona: Gustavo Gili, 1997.

SEVTSUK, A., MEKONNEN, M. Urban Network Analysis Toolbox. International Journal of Geomatics and Spatial Analysis, v.22, n.2, p. 287-305, 2012. DOI: https://doi.org/10.3166/RIG.22.287-305.

STUCHI, R.; LEITE, C. Plano de Desenvolvimento Urbano Estratégico de Nova Friburgo 2050. Disponível em: https://stuchileite.wixsite.com/stuchileite/urb12-nova-friburgo. Acesso em 20 jul. 2019. Acesso em: 23 ago. 2020.

SUZUKI, H.; CERVERO, R.; IUCHI, K. Transforming Cities with Transit: Transit and Land-Use Integration for Sustainable Urban Development. Washington: World Bank, 2013.

VERNIZ, D.; DUARTE, J. P. Santa Marta Urban Grammar: Unraveling the spontaneous occupation of Brazilian informal settlements. Environment and Planning B: Urban Analytics and City Science, 2020. DOI: https://doi.org/10.1177/2399808319897625

ZAMBRANO, L. M. A. A experiência do Escritório Escola Itinerante do curso de Arquitetura e Urbanismo da UFJF no condomínio Vivendas Belo Vale em Juiz de Fora - MG. Terceiro Milênio - Revista Crítica de Sociologia e Política, v.5, n.2, p. 85-112, 2015.

\footnotetext{
${ }^{1}$ Fernando Tadeu de Araújo Lima

Arquiteto e Urbanista, Doutor em Urbanismo (2017) pelo Programa de Pós-graduação em Urbanismo da Universidade Federal do Rio de Janeiro (PROURB UFRJ). Professor Adjunto da Universidade Federal de Juiz de Fora e Professor Visitante no Stuckeman Center for Design Computing - Pennsylvania State University. Endereço postal: Campus Universitário, Rua José Lourenço Kelmer, s/n, São Pedro, Juiz de Fora, MG, Brasil, 36036-900.
}

\section{${ }^{2}$ Carlos Frederico Ribeiro Costa}

Arquiteto e Urbanista, Especialista em Arquitetura e Cidade (2017), Mestre em Ambiente Construído (2020) pelo Programa de Pós-graduação em Ambiente Construído da Universidade Federal de Juiz de Fora (PROAC UFJF). Doutorando em Arquitetura e Urbanismo do Programa de Pós-graduação em Arquitetura e Urbanismo da Universidade Federal da Paraíba (PPGAU UFPB).

\section{Ashiley Adelaide Rosa}

Arquiteta e Urbanista pela Faculdade de Arquitetura e Urbanismo da Universidade Federal de Juiz de Fora (FAU UFJF). Mestre em Ambiente Construído (2020) pelo Programa de Pós-graduação em Ambiente Construído da Universidade Federal de Juiz de Fora (PROAC UFJF).

${ }^{4}$ Luiza Fischer Costa Vallone

Arquiteta e Urbanista pela Faculdade de Arquitetura e Urbanismo da Universidade Federal de Juiz de Fora (FAU UFJF). 